\title{
Quality of Life for Elderly Residents in Nursing Homes
}

\author{
Fereshteh Farzianpour ${ }^{1}$, Abbas Rahimi Foroushani ${ }^{2}$, Abbas Badakhshan ${ }^{1}$, Mahin Gholipour ${ }^{3} \&$ Esmaeil \\ Hosseinzadeh Roknabadi ${ }^{1}$ \\ ${ }^{1}$ Department of Health Management and Economics, School of Public Health, Tehran University of Medical \\ Sciences, Tehran, Iran \\ ${ }^{2}$ Department of Epidemiology and Biostatistics, Tehran University of Medical Sciences, Tehran, Iran \\ ${ }^{3}$ Golestan Research Center for Gastroenterology and Hepatology at Golestan University of Medical Sciences in \\ Gorgan, Iran \\ Correspondence: Fereshteh Farzianpour, Department of Health Management and Economics, School of Public \\ Health, Tehran University of Medical Sciences, Tehran, Iran. E-mail:farzianp@sina.tums.ac.ir
}

Received: June 5, 2015 Accepted: June 23, 2015 Online Published: July 30, 2015

doi:10.5539/gjhs.v8n4p127

URL: http://dx.doi.org/10.5539/gjhs.v8n4p127

\begin{abstract}
Background and Objectives: More than $8 \%$ of Iran's populations are elderly. The greatest challenge in this generation is improvement of health and QoL.The main goal of this study was QoL for elderly residents in nursing homes over 65 years in Golestan Province - Iran.
\end{abstract}

Methods: This research was an analytical cross study. The population society includes the elderly over 65 years in Golestan Province - Iran. The sample size was calculated based on the correlation of 193 elderly men and women. Therefore, if the correlation is 2.0 or greater is statistically significant at $80 \%$ and 0.95 confidence.

The needed data collected from two questionnaires Consumer product Safety Commission (CPSC) to assess the QOL of nursing homes and the SF-36 for health QOL the elderly indicators through interviews and observation. The reliability of the CPSC questionnaire was estimated using Cronbach's alpha with a coefficient of 0.838 . The SF-36 questionnaire was validated with Cronbach's alpha with a coefficient of 0.95 . To analyze data, ANOVA one-way test was used that after investigating homogenization of variances with Levin statistic, if homogenization reported $\mathrm{P}$ is rejected, the independent T-test was used to interpret it.

Results: Among QOL dimensions only General Health $(\mathrm{GH})$ status showed a significant association with supporting organizations covering status $(\mathrm{P}=0.01)$. The relationship between QOL with marital status in both genders was observed that the General Health $(\mathrm{GH})(\mathrm{P}=0.001)$, Physical Functioning $(\mathrm{PF}) \mathrm{P}=(0.007)$ Mobility Restricts (MR) $\mathrm{P}=(0.002)$, Emotional Problems (EP) $(\mathrm{P}=0.001)$, vitality $(\mathrm{V})(\mathrm{P}=0.001)$, Mental Health $(\mathrm{MH})$ $(\mathrm{P}=0.001)$ were significantly related.

Conclusions: There was a significant relationship between the Physical Functioning (PF) mean and the mean of other QOL indicators in two groups of male and female $(\mathrm{P}=0.007)$, also the safety of nursing homes just related respectively with residence variable $(\mathrm{P}=0.01)$ and their employment $(\mathrm{P}=0.031)$.

Keywords: Quality of Life, elderly, nursing homes, Questionnaires (SF36) and (CPSC), Iran

\section{Background}

The world's population is aging (Rakhshani et al., 2014). More than $8 \%$ of Iran's populations are elderly (Farzianpour et al., 2015). The greatest challenge in this generation is improvement of health and QoL (Farzianpour et al., 2014). QoL subscales were influenced by different factors including age, gender, and financial status and more importantly by health, education, financial and marital status (Farzianpour et al., 2012) Elderly people's health and QoL, when compared with other age groups, are influenced by several factors such as physical, psychological, social and cultural rights (Farzianpour et al., 2012); so that when considering the elderly's health assessment and promotion, the knowledge of an entire health team shall be also considered since it is important for health professionals to work in multidisciplinary and multidimensional teams. Regarding the elderly care, it is necessary to estimate the maintenance of QoL, so that the whole human aging process is considered always seeking for the possibilities of prevention, maintenance and rehabilitation of their health 
condition (Farzianpour et al., 2004). The improvement in the living conditions has led to the phenomena of aging in different societies (AK, 2010; Kinsella et al., 2005).

Like other countries, Iran has experienced a shift in the population structure towards aging so that according to statistics in 2011, 8.19\% of Iran's Populations were older than 60 years (Statistical Yearbook of Islamic Republic of Iran Management and Planning Organization, 2007). As aging is considered an important social issue worldwide, the biggestchallenge is improving the quality of life (QoL) in the elderly (Vameghi et al., 2007; Malekafzali et al., 2010).

QoL is a multidimensional concept that includes the individual's physical, psychological and social performances (Revicki, 1989). The increase of human's life span emphasis the importance of the health-promoting behavior in maintaining and improving QoL (Lee et al., 2006; Lucile et al., 2005; Resnick et al., 2003).

The World Health Organization has placed an emphasis on the importance of health-promoting behavior as a key strategy for maintaining a good QoL (WHO 2002). Pender et al. classified the health-promoting lifestyle (HPL) into six subcategories of nutrition, physical activities, stress management, health responsibility, interpersonal relations, and spiritual growth (Pender et al., 2005).

In Iran, researches have been conducted on different age groups, except the elderly, regarding the association between HPL and QoL (Shankar et al., 1986; Mohamadian et al., 2011).

In developed countries, the association of one or two subscales of HPL with QoL in the elderly have been investigated, which have mainly dealt with the aspect of nutrition and physical activity and the results have indicated that nutrition and physical activities are effective factors in QoL of the elderly (Sohng et al., 2002; Rejeski et al., 2001; McNaughton et al., 2012; Weiwen et al., 2012).

A study in China indicated that interpersonal relations, spiritual growth, and physical activities were better predictors for QoL in older than 50 years of age retired people (Zhang et al., 2013; Zhang et al., 2013). Despite some similarities between the elderly in Iran and the elderly in developed countries, the cultural, religious, and environmental issues should not be neglected (Sonay, 2012). In Iran, the results of a study by Aghanuri et al. have indicated that the quality of nutrition does not have a significant association with the QoL in the elderly (Aghanuri et al., 2013). On the contrary, researches in developed countries show a significant association between nutrition and QoL in the elderly (Kvamme et al., 2011; Keller et al., 2004; Amarantos et al., 2001). Knowledge about the factors that influence QoL is important as population aging becomes a worldwide reality (Lee et al., 2006).

There is less evidence about the amount of influence of HPL on the health-related QoL (HRQoL) in the Iranian elderly and it should be considered that any designed and executed strategy for health promotion needs evidence-based science, because if there is no awareness and recognition of the status of the society's health factors, health programs may just impose high costs. Hence, the results of this study can help health specialists, managers, and policymakers to design and execute health-promoting strategies based on the evidences, and prepare a basis for further researches in the field of aging. The present study assessed QoL using the SF-36 questionnaire to investigate the effects of factors such as age, sex, education, occupation and residence, married status and supporting organizations covering status. The CPSC questionnaire was used to assess the health of the homes nursing environment for elderly residents and its relationship between QoL.

\section{Methods}

This research was approved by the Vice-Chancellor for Research of Tehran University of Medical Sciences and the Research and Ethics Committee as \#19430-123225 on 27 March 2012. The study is an analytical cross-sectional study with descriptive and analytical parts. The population was individuals over 65 years of age in the province of Golestanin Iran. In the first phase, the number of elderly in nursing homes in Golestan province was determined. Next, samples were selected from the population of the nursing homes. For sampling, each nursing home was considered to be a cluster for which simple random sampling was carried out and which were surveyed.

The goal was to investigate the association between QoL scores and satisfaction scores in nursing homes. The sample size was calculated based on a correlation coefficient; a correlation of 0.2 or greater is statistically significant at $80 \%$ for power of test at a $95 \%$ confidence level. The sample size was calculated as:

$$
\begin{gathered}
\mathrm{r}=0.2 ; \mathrm{w}=0.203 ; \mathrm{Z} 1-\mathrm{a} / 2=1.96 ; \mathrm{Z} 1-\mathrm{b}=0.84 \\
\mathrm{n}=(\mathrm{Z} 1-\mathrm{a} / 2+\mathrm{Z} 1-\mathrm{b})^{\wedge} 2 / \mathrm{w}^{\wedge} 2+3=199
\end{gathered}
$$


Since each nursing home was considered to be a cluster and there are only five nursing homes in Golestan province, all were studied; thus, the sample size was multiplied by the ratio of cluster sampling (1.5) and the size of sample was obtained as follows:

$$
\mathrm{n}=199 \times 1.5=298.5
$$

Because the study population was limited $(\mathrm{n}=350)$, the number of samples was adjusted according to the following formula for a final research population of about 193 elderly individuals attending the Jahandidegan Geriatric Charity Institute in the city of Golestan.

$$
n^{*}=\frac{n_{0}}{1+\frac{n_{0}}{N}}=198.5 /(1+198.5 / 350)=193
$$

Data was collected using the CPSC questionnaire to measure QoL in nursing homes and the SF36 questionnaire to determine quality indicators. The results were analyzed using SPSS V.17software.

The questionnaires consisted of two parts. The first part obtained demographic and other background information that is assumed to affect QoL and quality indicators of the elderly. The second part contained questions related to QoL. The SF-36 questionnaire scored all questions and the general QoL quantitatively on a scale from 0 to 100 . The questionnaires were completed by interview and observation.

The SF-36 consists of 8 dimensions: physical functioning (PF), mobility restriction (MR), bodily pain (BP), general health $(\mathrm{GH})$, vitality $(\mathrm{V})$, social functioning $(\mathrm{SF})$, emotional problems (EP) and mental health (MH). Each dimension was scored from 0 through 100. The SF-36has been validated by Montazeri et al. (2005) as having aCronbach'salpha coefficient of 0.95 for the Iranian population (Montazeri et al., 2005; Mohamadian et al., 2011).

The CPSC questionnaire had 54 items and each item had two options (yes/no). The CPSC has been validated by Farzianpour et al. (2015). The reliability of the CPSC questionnaire was estimated using Cronbach's alpha with a coefficient of 0.838 (Farzianpour et al., 2004, 2015). The chi square test and logistical regression were used to interpret the probability of abnormal QoL between levels of independent predictors. The intra-class correlation coefficient showed that the internal consistency of items on the CPSC was acceptable with an average of 0.815 .

Data were analyzed using the chi-square test for one-variable analysis and logistic regression modeling for multi-variable analysis.

\section{Ethical Considerations}

All participants were given a full explanation of the study and freely consented to participate in the research. The questionnaires did not contain the names of the participants and they were assured that the information collected would be kept confidential and under no circumstances would the published results contain the names of the participants.

\section{Results}

In this study $17.8 \%$ of the elderly were men and 82.2 were women. $62 \%$ of these people were married, $20.5 \%$ of them illiterate. 92.93 percent insurance, 7.1 percent without any support services. In terms of employment of participants also 5.29 percent were unemployed (Table 1).

\begin{tabular}{|c|c|c|c|}
\hline variables & $\mathrm{N}(\%)$ & variables & $\mathrm{N}(\%)$ \\
\hline Gender & & Education & \\
\hline male & $33(17.8)$ & illiterate & $39(20.5)$ \\
\hline Female & $152(82.2)$ & Primary & $68(35.8)$ \\
\hline Total & $185(100)$ & High school & $41(21.6)$ \\
\hline Residence & & Diploma & $34(17.9)$ \\
\hline Urban & $33(18.6)$ & Upper Diploma & $6(3.2)$ \\
\hline Rural & $144(81.4)$ & B.S & $2(1.1)$ \\
\hline Total & $177(100)$ & Total & $190(100)$ \\
\hline
\end{tabular}

Table 1. Distribution frequency and demographic variables (\%) population 


\begin{tabular}{llll}
\hline Marital & \multicolumn{3}{c}{ Employment } \\
Single & $10(5.4)$ & Unemployed & $4(2.1)$ \\
Married & $114(62)$ & Employed & $17(1.9)$ \\
Divorced & $6(3.3)$ & Fulltime & $8(4.2)$ \\
Widow & $54(29.3)$ & Part time & $9(4.7)$ \\
Total support services & $184(100)$ & Housewives & $125(66.1)$ \\
Relief Committee & $11(6)$ & Farmers & $20(10.6)$ \\
Welfare & $3(1.6)$ & Retirees & $6(3.2)$ \\
Health care & $68(37)$ & Total & $189(100)$ \\
Social security & $65(35.3)$ & & \\
Military & $13(7.1)$ & Total & $189(100)$ \\
\hline
\end{tabular}

Table 2 showed that among QoL dimensions (PF,MR,EP,V and MH) in both genders, so among QoL dimensions (MR, MH,SF and $\mathrm{GH}$ ) in both genders of elderly that living in Urban and rural, QoL dimensions (PF, MR,EP ,V,BP,GH) for marital status and QoL dimensions (PF, SF,BP,GH) for education status were significantly related $(\mathrm{P}<0.05)$. Table 3 showed that association between the CPSC scores and socio-demographical characteristics of the study sample that only variables Residence.

Table 2. SF-36 scores versus socio-demographical characteristics of study sample for gender, residence, and marital status

\begin{tabular}{|c|c|c|c|c|c|c|c|c|c|c|c|}
\hline \multirow[t]{2}{*}{ Scales } & \multicolumn{2}{|c|}{ Sex } & \multirow[t]{2}{*}{$\begin{array}{c}P \\
\text { value }\end{array}$} & \multicolumn{2}{|c|}{ Residence } & \multirow[t]{2}{*}{$\begin{array}{c}P \\
\text { value }\end{array}$} & \multicolumn{4}{|c|}{$\begin{array}{c}\text { Marital Status } \\
\text { mean (SD) }\end{array}$} & \multirow[t]{2}{*}{ P value } \\
\hline & $\begin{array}{l}\text { Male } \\
\text { mean } \\
\text { (SD) }\end{array}$ & $\begin{array}{c}\text { Female } \\
\text { mean } \\
(\mathrm{SD})\end{array}$ & & $\begin{array}{c}\text { Urban } \\
\text { mean } \\
\text { (SD) }\end{array}$ & $\begin{array}{c}\text { Rural } \\
\text { mean } \\
\text { (SD) }\end{array}$ & & Single & Married & Divorced & Widow & \\
\hline PF & $62.72(20.84)$ & $50.26(32.34)$ & 0.007 & $52.67(32.67)$ & $51.6(21.12)$ & 0.866 & $49(17.28)$ & $6.04(28.54)$ & $58.33(34.59)$ & $36.57(30.12)$ & 0.01 \\
\hline MR & $63.63(38.57)$ & $38.65(45.74)$ & 0.002 & $37.32(45.41)$ & $59.0(38.43)$ & 0.006 & $50(52.70)$ & $53.72(4.40)$ & $45.83(51.03)$ & $20.37(36.68)$ & 0.001 \\
\hline EP & $82.32(32.79)$ & $57.38(45.32)$ & 0.001 & $60.04(45.06)$ & $70.7(39.75)$ & 0.213 & $50(47.49)$ & $47.33(38.77)$ & $80(44.72)$ & $38.36(44.04)$ & 0.001 \\
\hline $\mathbf{V}$ & $66.81(16.28)$ & $56.08(17.66)$ & 0.001 & $57.12(18.16)$ & $57.62(13.95)$ & 0.883 & $52.66(9.46)$ & $61.44(18.25)$ & $60(20.49)$ & $51.88(16.75)$ & 0.009 \\
\hline MH & $68.51(16.15)$ & $57.13(18.06)$ & 0.001 & $56.38(18.74)$ & $65.75(13.95)$ & 0.01 & $63.20(20.81)$ & $61.25(17.82)$ & $52.66(34.63)$ & $55.07(16.21)$ & 0.144 \\
\hline SF & 58.71(15.77) & $63.89(26.70)$ & 0.284 & $65.19(26.28)$ & $54.54(19.96)$ & 0.012 & $67.50(28.98)$ & $66.66(23.14)$ & $58.33(24.57)$ & $56.48(22.55)$ & 0.075 \\
\hline BP & $69.24(13.10)$ & $62.53(22.18)$ & 0.096 & $63.69(22.13)$ & $65.07(15.92)$ & 0.736 & $58.50(22.11)$ & $68.53(19.13)$ & $53.75(17.37)$ & $57.26(22.14)$ & 0.004 \\
\hline GH & $56.51(8.61)$ & $55.51(17.42)$ & 0.749 & $57.43(16.77)$ & $50.87(12.28)$ & 0.013 & $48(19.17)$ & $59.68(13.83)$ & $38.33(25.81)$ & $51.29(16.34)$ & 0.001 \\
\hline
\end{tabular}


Table 3. SF-36 scores versus socio-demographical characteristics of study sample for Education and Employment

\begin{tabular}{|c|c|c|c|c|c|c|c|c|c|c|c|}
\hline \multirow[t]{2}{*}{ Scales } & \multicolumn{6}{|c|}{ Education mean (SD) } & \multirow{2}{*}{$\begin{array}{c}\text { P } \\
\text { value }\end{array}$} & \multicolumn{4}{|c|}{ Employment mean (SD) } \\
\hline & Illiterate & Primary & High school & Diploma & $\begin{array}{c}\text { Upper } \\
\text { diploma }\end{array}$ & BS & & Unemployed & Employee & Fulltime & Part-time \\
\hline PF & $37.82(28.39)$ & $56.25(28.07)$ & $58.53(32.56)$ & $52.18(33.69)$ & $64.16(31.68)$ & $75(14.14)$ & 0.019 & $51.25(39.66)$ & $51.66(31.75)$ & $68.33(17.13)$ & $55.35(30.02)$ \\
\hline MR & $28.84(39.95)$ & $48.89(44.97)$ & $44.51(48.5) 7$ & $41.91(46.35)$ & $58.33(46.54)$ & $25(35.35)$ & 0.303 & $60(45.41)$ & $33.33(28.86)$ & $52.77(40.39)$ & $50(45.99)$ \\
\hline EP & $50.42(74.06)$ & $70.83(39.93)$ & $55.83(46.15)$ & $63.02(44.34)$ & $83.33(40.82)$ & $1.00(0.00)$ & 0.104 & $66.66(47.14$ & $66.66(57.73)$ & $90.74(18.83)$ & $80.95(25.19)$ \\
\hline $\mathbf{V}$ & $53.84(17.48)$ & $61.76(17.75)$ & $58.3(16.54)$ & $53.57(19.27)$ & $65(17.82)$ & $67.50(24.74)$ & 0.124 & $66(28.15)$ & 44.44 & 68.51 & 55.59 \\
\hline MH & $60.35(16.26)$ & $61.47(17.43)$ & $56.21(21.93)$ & $54.73(15.79)$ & $71.50(18.19)$ & $60(5.65)$ & 0.207 & $68.80(18.41)$ & $51.66(7.63)$ & $73.77(10.02)$ & $62.85(17.64)$ \\
\hline SF & $49.35(21.64)$ & $62.68(23.10)$ & $65.54(26.92)$ & $70.22(24.42)$ & $95.83(6.45)$ & $75(35.35)$ & 0.01 & $70(22.70)$ & $62.50(21.65)$ & $54.16(28.64)$ & $58.03(20.57)$ \\
\hline BP & $55.44(17.71)$ & $67.09(21.89)$ & $62.68(20.94)$ & $65.95(19.69)$ & $78.75(23.86)$ & $77.50(31.81)$ & 0.031 & $77(15.94)$ & $5.16(18.76)$ & $88.11(12.87)$ & $65.35(12.43)$ \\
\hline GH & $47.53(16.21)$ & $58.75(13.47)$ & $52.43(19.64)$ & $61.02(13.18)$ & $65(7.74)$ & $72.50(17.67)$ & 0.01 & 62 & 60 & 57.63 & 57.50 \\
\hline
\end{tabular}

Employment were significantly related respectively $(\mathrm{P}=0.01$ and $\mathrm{p}=0.031)$ Table 4 showed that among QoL dimensions only General Health $(\mathrm{GH})$ status showed a significant association with supporting organizations covering status $(\mathrm{P}=0.01)$. Analysis of the data showed that among $\mathrm{QoL}$ dimensions with Physical Functioning (PF) and Mental Health (MH) only (PF) status a significant association with marital status, education respectively ( $\mathrm{P}=0.01$ and $\mathrm{p}=0.019)$ so Mental Health $(\mathrm{MH}))$ status only with current employment status $(\mathrm{P}=0.005)$ (Table 4).

Table 4. Determinants of physical functioning and mental health related quality of life in elderly participants

\begin{tabular}{|c|c|c|c|c|}
\hline Scales & Marital Status & \multicolumn{2}{|c|}{$95 \% \mathrm{CI}$} & P-value \\
\hline & & Lower & Upper & \\
\hline \multirow[t]{5}{*}{ Physical functioning } & Single & 36.63 & 61.36 & 0.01 \\
\hline & Married & 54.69 & 65.39 & \\
\hline & Divorced & 22.03 & 94.63 & \\
\hline & Widow & 28.35 & 44.79 & \\
\hline & Total & 47.96 & 56.86 & \\
\hline \multirow[t]{5}{*}{ Mental Health } & Single & 48.31 & 78.08 & 0.144 \\
\hline & Married & 57.94 & 64.56 & \\
\hline & Divorced & 16.32 & 89.01 & \\
\hline & Widow & 50.64 & 59.50 & \\
\hline & Total & 56.59 & 61.93 & \\
\hline \multirow[t]{8}{*}{ Physical functioning } & Education & & & \\
\hline & Illiterate & 28.61 & 47.02 & 0.019 \\
\hline & Primary & 49.45 & 63.04 & \\
\hline & High school & 48.25 & 68.81 & \\
\hline & Diploma & 40.03 & 64.33 & \\
\hline & Upper diploma & 30.91 & 97.42 & \\
\hline & $\mathrm{BS}$ & -52.06 & 202.06 & \\
\hline & Total & 48.23 & 57.13 & \\
\hline
\end{tabular}


Table 4. Continued

\begin{tabular}{|c|c|c|c|c|}
\hline \multirow[t]{8}{*}{ Mental Health } & Education & 2.60 & 65.62 & 0.207 \\
\hline & Illiterate & 2.11 & 65.69 & \\
\hline & Primary & 3.42 & 63.14 & \\
\hline & High school & 2.70 & 60.24 & \\
\hline & Diploma & 7.42 & 90.59 & \\
\hline & Upper diploma & 4 & 110.82 & \\
\hline & BS & 1.31 & 61.79 & \\
\hline & Total & 1.31 & 61.79 & \\
\hline \multirow[t]{10}{*}{ Physical functioning } & Employment & & & \\
\hline & Unemployed & -11.85 & 114.35 & \\
\hline & Employee & -27.21 & 130.54 & \\
\hline & Fulltime & 55.15 & 81.50 & \\
\hline & Part-time & 38.01 & 72.69 & \\
\hline & Unemployedwith income & -21.52 & 138.18 & \\
\hline & Housewives & 42.55 & 54.38 & \\
\hline & Farmers & 50.41 & 75.95 & \\
\hline & Retirees & 47.63 & 72.36 & \\
\hline & Total & 47.81 & 56.80 & \\
\hline \multicolumn{5}{|l|}{ Table 4. Continued } \\
\hline \multirow[t]{11}{*}{ Mentall Health } & & & & 0.005 \\
\hline & Employment & & & \\
\hline & Unemployed & 45.93 & 91.66 & \\
\hline & Employee & 32.69 & 70.63 & \\
\hline & Fulltime & 66.07 & 81.48 & \\
\hline & Part-time & 52.67 & 73.04 & \\
\hline & Unemployedwith income & -40.07 & 125.40 & \\
\hline & Housewives & 53.59 & 59.79 & \\
\hline & Farmers & 63.17 & 83.00 & \\
\hline & Retirees & 49.82 & 68.00 & \\
\hline & Total & 56.63 & 61.86 & \\
\hline \multirow[t]{9}{*}{ General Health } & Organizations support services & & & 0.01 \\
\hline & Relief Committee & 29.09 & 72.52 & \\
\hline & Welfare & 25.81 & 77.52 & \\
\hline & Health care & 48.91 & 57.26 & \\
\hline & Social security & 56.40 & 62.48 & \\
\hline & Military & 59.18 & 76.20 & \\
\hline & Insurance Supplementary & 48.48 & 91.51 & \\
\hline & Other & 52.74 & 68.50 & \\
\hline & Total & 53.64 & 58.29 & \\
\hline
\end{tabular}

\section{Discussion}

In general, the obtained scores of SF-36 in this study showed QOL in the elderly were significantly correlated with gender and indicate that males scores higher for QoL than did females. Results of this study were correlated with the more negative attitude of females toward their physical health. The results of the CPSC questionnaire, 
which was used for the first time in research in Iran, showed that the perception of safety of residence in $98 \%$ of cases was moderate $(47.7 \%)$ or good $(50.3 \%)$. The study found that the CPSC results correlated significantly with residence for a moderate level of safety for nursing homes in rural areas and a good level of safety in urban areas. CPSC results also showed a significant relationship with level of employment. The results from the CPSC and SF-36 showed a significant relationship only between the CPSC and physical constraints. Our findings support previously described beneficial effects of the counseling model on the elderly QoL in the cities of Tehran (Farzianpour et al., 2004., Rakhshani et al.,2014) Masjed solaiman (Farzianpour et al., 2012), Marivan (Farzianpour et al .,2012 ), Iran. The mean QoL scores measured in the elderly population, in other countries were much higher than the results obtained in Iran (Tsai et al .,2004). The QoL subscales were influenced by different factors including age, gender, and financial status and more importantly by education, financial and marital status as other studies showed (Farzianpour et al., 2012). Therefore, it is important to inform the elderly population of the behavioral modifications benefits of the QoL. The study of Farzianpour et al also found clear connections between disability and gender and the higher rate of failure in women (Farzianpour et al., 2015).

Gureje and colleagues also point out that the bodily pain which can lead to reduced QoL was higher in women that this issue could be due to a greater incidence of chronic disabling diseases in women than in men (Gureje et al., 2006).

However the study of Farzianpour et al., found that women in vitality and mobility restrict aspects were better than men (Farzianpour et al., 2015).

\section{Conclusions}

It seems that dimensions of QoL are more related to gender and relative superiority of men over women. So the policy makers of health sector should pay more attention to the social factors affecting health such as education, housing and the physical functioning. Particularly that the illiteracy rate among women was higher than men, and also a lot of them were housewives that were an unpaid work and therefore didn't create any sense of security.

It also seems that due to physiological and anatomical features of women and men, physically activity facilities for women should have provided more and economic and social barriers to be eliminated as soon as possible. It seems that some restrictive measures such as the establishment of special parks in Golestan Province or some other metropolises are not an appropriate strategy to address this deficiency. Relating with different dimensions of $(\mathrm{QoL})$ and age of participants, it is seen that with increasing age of the participants in terms of bodily pain, mobility restricts and mental health increases, this is necessary for authorities to pay attention to these issues and programs to improve their physical activities and specially their mental health.

Overall, this study and other studies suggest that aging alone was not particularly effective on the QoL dimensions especially on mental health and other aspects of life in the elderly.

\section{Limitations}

The limitations of this study included several changes in management of the State Welfare Organization of the province that delayed the implementation phase of the project. Other restrictions were the lack of cooperation by some elderly for completing the questionnaire and it was necessary to fully explain all options to them. In some cases, educated and interested members of their households were asked to encourage and explain the importance of the project, especially regarding questions on the CPSC questionnaire.

\section{Competing Interests}

The authors declare that they have no competing interests that may be perceived to influence the results and discussion reported in this manuscript.

\section{Authors' Contributions}

FF has made substantial contribution to initial idea and design and FF, ARF, AB conducted statistical analyses and interpretation of data. FF, ARF, AB, MGH and EHR participated in the survey and drafted the manuscript. All authors read and approved the final manuscript.

\section{Acknowledgements}

This work was supported by the School of Public Health (SPH) of Tehran University of Medical Sciences (TUMS).The interviews were funded by SPH. The study was conducted as a component of the elderly project, which is funded by TUMS. We appreciate the kind collaboration of Mr. Kamal Salmani, Deputy for Rehabilitation Services of Golestan Province and Mr.Ahangari. We would like to thank the elderly of Golestan Province for their careful completion of our questionnaires. 


\section{References}

Aghanuri, A., Mahmoudi, M., Asadi, M., Mortaji, F., Salehi, H., Djafarian, K., et al. (2013). Quality of life and its relationship with quality of diet among elderly people in urban areas of Markazi province, Iran, Arak. Medic Uni J., 15(68), 1-11 (in Persian).

AK, P. (2015). Determinants of Living Arrangements of Elderly in Orissa, India, Asia. Pac Popul J., 25.

Amarantos, E., Martinez, A., Dwyer, J. (2001). Nutrition and Quality of Life in Older Adults. Biol Sci Medic Sci. 56(Supplement 2), 54-64. http://dx.doi.org/10.1093/gerona/56.suppl_2.54

Farzianpour, F., Foroushani, A. R., Badakhshan, A., \& Gholipour, M. (2015). The Relationship between Quality of Life with Demographic Variables of Elderly in Golestan Province-Iran. Health, 7, 507-513. http://dx.doi.org/10.4236/health.2015.75060

Farzianpour, F., Farokhi, B., Shojaei, S., Shafi, M., \& Manafi, F. (2014). Status of the Elderly Health Care Costs. American Journal of Agricultural and Biological Sciences, 9, 147-152. http://dx.doi.org/10.3844/ajabssp.2014.147.152

Farzianpour, F., Arab, M., Hosseini, S. M., Pirozi, B., \& Hosseini, S. (2012). Evaluation of Quality of Life of the Elderly in 2010. Iranian Red Crescent Medical Journal, 14, 697-698. http://dx.doi.org/10.5812/ircmj.1834

Farzianpour, F., Hosseini, S. H., Rostami, M., Pordanjani, S. H., \& Hosseini, S. M. (2012). Quality of Life of the Elderly Residents. American Journal of Applied Sciences, 9, 71-74. http://dx.doi.org/10.3844/ajassp.2012.71.74

Farzianpour, F., \& Tajvar, M. (2004). Elderly Health and a Review on Different Aspects of Their Life. Nasle Farda and Arjmand Press, Tehran. Iran

Gureje, O., Ogunniyi, A., Kola, L., \& Afolabi, E. (2006). Functional Disability in Elderly Nigerians: Results from the Ibadan Study of Aging. Journal of the American Geriatrics Society, 54, 1784-1789. http://dx.doi.org/10.1111/j.1532-5415.2006.00944.x

Keller, H. H., Ostbye, T., \& Goy, R. (2004). Nutritional risk predicts quality of life in elderly community-living Canadians. J Gerontol A Biol Sci Med Sci, 59(1), 68-74. J Gerontol A Biol Sci Med Sci, 59(1), M68-M74. http://dx.doi.org/10.1093/gerona/59.1.M68

Kinsella, K., \& Phillips, D. R. (2005). Global Aging: The Challenge of Suc-cess. Popul Bulletin, Popul Reference Bureau, 1, 1-5.

Kvamme, J. M., Olsen, J. A., Florholmen, J., \& Jacobsen, B. K. (2011). Risk of mal-nutrition and health-related quality of life in community-living elderly men and women: the Tromso study. Qual Life Res, 20(4), 575-82. http://dx.doi.org/10.1007/s11136-010-9788-0

Lee, T. W., Ko, I. S., \& Lee, K. J. (2006). Health promotion behaviors and quality of life among community-dwelling elderly in Korea: a cross-sec-tional survey. Int J Nurs Stud., 43(3), 293-300. http://dx.doi.org/10.1016/j.jinurstu.2005.06.009

Lucile, C., Aure'lie, M., Nicole, C., Florence, C., Ge'lie, D., Ve'ronique, D-P, et al. (2005). Health Promotion In nursing practice. Pender NJ MCPM editor. New Jersey: Prentice Hall PTR www.ncbi.nlm.nih.gov

Malekafzali, H., Baradaran Eftekhari, M., Hejazi, F., Khojasteh, T., Noot, R. H., Falahat, K., et al. (2010). The Effectiveness of Educational Intervention in the Health Promotion in Elderly people. Iran J Public Health. 39(2), 18-23.

McNaughton, S. A.,. Crawford, D., Ball, K., \& Salmon, J. (2012). Understand-ing determinants of nutrition, physical activity and quality of life among older adults: the Wellbeing, Eating and Exercise for a Long Life (WELL) study. Health and Quality of Life Outcomes, 10(1), 109. http://dx.doi.org/10.1186/1477-7525-10-109

Mohamadian, H., Eftekhar, H., Rahimi, A., Mohamad, H. T., Shojaiezade, D., \& Montazeri, A. (2011). Predicting health-related quality of life by us $\neg$ ing a health promotion model among Iranian adolescent girls: a structural equation modeling approach. Nurs Health Sci., 13(2), 141-8.15 http://dx.doi.org/10.1111/j.1442-2018.2011.00591.x

Montazeri, A., Goshtasebi, A., Vahdaninia, M., \& Gandek, B. (2005). The Short Form Health Survey (SF-36): Translation and validation study of the Iranian version. Quality of Life Research, 14(3), 875-82. http://dx.doi.org/10.1007/s11136-004-1014-5 
Rakhshan, T., Shojaiezadeh, D., Bagheri Lankarani, K., Rakhshani, F., Kaveh, M. H., \& Zare, N. (2014). The Association of Health-Promoting Life style with quality of life among the Iranian elderly. Iran Red Crescent Med J., 16(9), e18404. http://dx.doi.org/10.5812/ircmj.18404

Pender, N. J., Muraugh, C. L., \& Parsons, M. A. (2005). Health Promotion In nursing practice. New Jersey: Prentice Hall PTR

Revicki, D. A. (1989). Health-related quality of life in the evaluation of med-ical therapy for chronic illness. $J$ Fam Pract., 29(4), 377-80.

Rejeski, W. J., \& Mihalko, S. L. (2001). Physical Activity and Quality of Life in Old $\neg$ er Adults. Biological Sciences and Medical Sciences, 56(Sup ־plement 2), 23-35. http://dx.doi.org/10.1093/gerona/56.suppl_2.23

Resnick, B. (2003). Health promotion practices of older adults: testing an individualized approach. $J$ Clin Nurs. 12(1), 46-55. http://dx.doi.org/10.1046/j.1365-2702.2003.00700.x

Shankar, R., Tuyethong, N., \& Sallis, J. D. (1986). Atherogenesis. Mitigation of monocyte adhesion to arterial endothelium in hyperlipidemic rats by phosphocitrate, a phosphorylated polycarboxylic acid. Atherosclerosis. 62(1), 47-54. [PubMed] http://dx.doi.org/10.1016/0021-9150(86)90018-3

Statistical Yearbook of Islamic Republic of Iran Management and Planning Organization. (2007). Tehran. Satake Center Ir J. URL: www.amar.org.ir

Sohng, K. Y., Sohng, S., \& Yeom, H. A. (2002). Health-Promoting Behaviors of El $\neg$ derly Korean Immigrants in the United States. Public Health Nurs $\neg$ ing. 19(4), 294-300. http://dx.doi.org/10.1046/j.1525-1446.2002.19409.x

Sonay, A. (2012). Quality of life for elderly people in iran with service de $\urcorner$ sign approach.

Vameghi, R., Niksirat, Z., Hatamizadeh, N., Kazemnejad, A., \& Health-related. (2010). Quality of Life in Retired Older People in Tehran City. Jour-nal of Applied Gerontology. 31(2), 155-72. http://dx.doi.org/10.1177/0733464810382413

Weiwen, C., Claudio, R. N., Ian, S. P., Robert, W. M., Caroline, H., \& Rod, K. D. (2010). Fruit and vegetable consumption, and physical inactivity in a free living, multiethnic population in Hawaii. International Jour $\neg$ nal of Behavioral Nutrition and Physical Activity.

World Health Organization. (2002). Noncommunicable Diseases and Men $\neg$ tal Health Cluster. Geneva: A policy framework.

Zhang, S. C., Tao, F. B., Ueda, A., Wei, C. N., \& Fang, J. (2013). The influence of health-Promoting lifestyles on the quality of life of retired workers in a medium-sized city of Northeastern China. Environ Health Prev Med, 18(6), 458-65. http://dx.doi.org/10.1007/s12199-013-0342-x

\section{Copyrights}

Copyright for this article is retained by the author(s), with first publication rights granted to the journal.

This is an open-access article distributed under the terms and conditions of the Creative Commons Attribution license (http://creativecommons.org/licenses/by/3.0/). 